\title{
Role of $\alpha$-Synuclein in Presynaptic Dopamine Recruitment
}

\author{
Leonid Yavich, ${ }^{1,2}$ Heikki Tanila, ${ }^{2,4}$ Saila Vepsäläinen, ${ }^{2,3}$ and Pekka Jäkälä ${ }^{2,4}$ \\ Departments of ${ }^{1}$ Pharmacology and Toxicology and ${ }^{2}$ Neuroscience and Neurology and ${ }^{3}$ Brain Research Unit, Clinical Research Centre/Mediteknia, \\ University of Kuopio, and ${ }^{4}$ Department of Neurology, University Hospital of Kuopio, FIN-70211 Kuopio, Finland
}

Real-time monitoring of stimulated dopamine release in mice with different $\alpha$-synuclein expression was used to study the role of $\alpha$-synuclein in presynaptic dopamine recruitment. Repeated electrical stimulations of ascending dopaminergic pathways decreased the capacity of the readily releasable pool (RRP) and temporarily increased its refilling rate, significantly slowing the rate of dopamine decline in mice with normally expressed $\alpha$-synuclein. Mice with $\alpha$-synuclein null mutation demonstrated a permanent increase of the refilling rate. This increase maintained stable dopamine release during stimulation (which induced dopamine decline in other animals) and served as an adaptation to altered dopamine compartmentalization. Mice without $\alpha$-synuclein and with overexpression of human A30P mutated $\alpha$-synuclein had a lower capacity of the dopamine storage pool than other animals. Reducing capacity of the storage pool in transgenic A30P mice led to paradoxical effects of L-dopa, which elevated dopamine release in response to single stimulation but decreased the refilling rate of the RRP.

Key words: dopamine; storage; $\alpha$-synuclein; null mutation; A30P transgenic mice; in vivo voltammetry

\section{Introduction}

Presynaptic mechanisms of dopamine compartmentalization in the storage pool and readily releasable pool (RRP) play an important role in adequate neurotransmission. During high-frequency firing and bursting of dopamine neurons, the RRP becomes exhausted and needs to be refilled from the storage pool. Several studies have shown that high-frequency stimulation of the dopaminergic pathways, which mimics bursting and exhausts the RRP, increases the refilling rate of the RRP (Ewing et al., 1983; Yavich, 1996; Yavich and MacDonald, 2000). Similar calciumdependent activation of refilling has also been described for fastacting neurotransmitters, such as GABA and glutamate (Rosenmund and Stevens, 1996; Stevens and Wesseling, 1998; Wang and Kaczmarek, 1998; Zucker, 1999). Although the refilling rate of the RRP and availability of dopamine in the storage pool are major determinants of the efficacy of dopaminergic neurotransmission, our knowledge of these processes is still fragmentary.

Among the currently known proteins that provide the machinery for dopamine recruitment, $\alpha$-synuclein ( $\alpha$-syn) is particularly interesting, because it has been proposed to be a key player in the pathogenesis of Parkinson's disease. Two missense $\alpha$-syn mutations (A30P and A53T) were recently found in families with autosomal-dominant Parkinson's disease (Polymeropoulos et al., 1997; Kruger et al., 1998). Mutations in $\alpha$-syn may alter the association of the protein with vesicular membranes, disrupting normal recycling of vesicles, which in turn can decrease the ca-

Received June 28, 2004; revised 0ct. 17, 2004; accepted 0ct. 20, 2004

This work was funded by Academy of Finland Grant 200858 (P.J.). We thank Professor Takeshi Iwatsubo for the generous gift of antibody LB509 and Hennariikka livonen and Mari Oksman for their help.

Correspondence should be addressed to Dr. L. Yavich, Department of Pharmacology and Toxicology, University of Kuopio, P.0. Box 1627, FIN-70211 Kuopio, Finland. E-mail: leonid.yavich@uku.fi.

DOI:10.1523/JNEUROSCI.2559-04.2004

Copyright $\odot 2004$ Society for Neuroscience $\quad$ 0270-6474/04/2411165-06\$15.00/0 pacity of vesicular storage and increase cytosolic levels of dopamine and its toxic metabolites (Lotharius and Brundin, 2002a,b).

Mice with deletion of the $\alpha$-syn gene demonstrate faster recovery of dopamine release after paired-pulse stimulation, lower levels of dopamine, and an attenuated response to amphetamine compared with wild-type mice (Abeliovich et al., 2000). A recent study showed that EPSPs in hippocampal slices decreased after long-lasting repetitive stimulation in $\alpha$-syn knock-out mice (Cabin et al., 2002). The authors suggested that this was caused by a disruption of the reserve storage pool of neurotransmitter, a function attributed to distantly located vesicles in the presynaptic terminals. This hypothesis is consistent with previous findings of reduced distantly located vesicles in hippocampal cultured neurons after $\alpha$-syn antisense oligonucleotide treatment (Murphy et al., 2000). However, these later studies did not test the dopaminergic system as such. Furthermore, nothing is known about adaptive changes in presynaptic terminals that may neutralize lack or mutation of this protein.

We combined real-time monitoring of dopamine release by in vivo voltammetry with repeated stimulation of ascending pathways, which exhaust dopamine storages, and drug treatments modulating the amount of presynaptic dopamine in mice with either absent or mutated $\alpha$-syn to shed light on the role of $\alpha$-syn in presynaptic terminals. We came to two basic conclusions. First, $\alpha$-syn alters compartmentalization of presynaptic dopamine and decreases capacity of the dopamine storage pool. Second, increase of the refilling rate of the RRP compensates for altered dopamine compartmentalization.

\section{Materials and Methods \\ Animals}

This study examined four different lines of C57BL/6 male mice. The first line was a subpopulation of C57BL/6 J mice originating from Harlan Olac (Bicester, UK) $\left(b 6 \mathrm{~m}^{-}\right)$, which carries a chromosomal deletion of the $\alpha$-syn locus and represents a knock-out model for $\alpha$-syn (Specht and 
Schoepfer, 2001). The second line was another subpopulation of C57BL/6J mice originating from Charles River Wiga (Sulzfeld, Germany) with no reported deletion of the $\alpha$-syn locus $\left(b_{6 m}{ }^{+}\right)$. This line was used as the wild-type control for the $\alpha$-syn knock-out mice. The third line was a transgenic mouse line carrying human $\alpha$-syn with A30P mutation, which was overexpressed under prion-protein promoter (Jakala et al., 2002). The line was established as C57BL/6J $\times$ DBA2 hybrids, and all subsequent backcrossings were made into the original background C57BL/6J strain (Charles River Wiga) that carries the endogenous mouse $\alpha$-syn (therefore referred to as $h^{+} m^{+}$mouse). The mice were first backcrossed into the $\mathrm{C} 57 \mathrm{BL} / 6 \mathrm{~J}$ strain for five generations; thereafter, a homozygous line was established by mating A30P mice for two generations before the present study. As described previously (Jakala et al., 2002), these mice display A30P $\alpha$-syn protein accumulation in the striatum and hippocampus, cortical layer IV, and cerebellar granule cells. However, there is no decline in tyrosine hydroxylase (TH) staining of striatum or substantia nigra. The fourth line stemmed from negative offspring of heterozygous A30P matings $\left(h^{-} \mathrm{m}^{+}\right.$mice). All of the mice were bred at a colony at the National Animal Center (Kuopio, Finland).

\section{Detection of mouse endogenous $\alpha$-synuclein gene and human $\alpha$-synuclein transgene}

Genomic DNA was isolated from the tail samples using Trizol reagent (Invitrogen, Renfrew, UK). PCR on $50 \mathrm{ng}$ of genomic DNA in a $10 \mu \mathrm{l}$ reaction volume included denaturation at $95^{\circ} \mathrm{C}$ for $60 \mathrm{sec}$, followed by 33 cycles at $95^{\circ} \mathrm{C}$ for $30 \mathrm{sec}, 60^{\circ} \mathrm{C}$ for $30 \mathrm{sec}$, and $72^{\circ} \mathrm{C}$ for $30 \mathrm{sec}$, and a final extension of $3 \mathrm{~min}$ at $72^{\circ} \mathrm{C}$. Specific primers amplified mouse $\alpha$-synuclein exon 6 (AGAAGACCAAAGAGCAAGTGACA and ATCTGGTCCTTCTTGACAAAGC; $130 \mathrm{bp}$ fragment) (Specht and Schoepfer, 2001) and human $\alpha$-synuclein transgene (GGAGGAGCAGTGGTGACG and TTCCTTCCTGTGGGGCT; 137 bp fragment). NMDA receptor subunit NR1 (exons 18-19; TCCATACTCAAGTGAGTCTGCCC and CAGGGGCATTGCTGCGGGAGTC; 508 bp fragment) was used as a positive control in each PCR (Specht and Schoepfer, 2001).

\section{In vivo voltammetry}

Preparation of animals. Mice were kept under the controlled conditions at the National Animal Center (temperature, $+21^{\circ} \mathrm{C}$; light from 7:00 A.M. to 7:00 P.M.; humidity, 50-60\%), with food and water available ad libitum. The experiments were conducted according to the Council of Europe (Directive 86/609) and Finnish guidelines and approved by the State Provincial Office of Eastern Finland.

The 12- to 14-month-old mice (35-40 gm) were anesthetized with chloral hydrate $(450 \mathrm{mg} / \mathrm{kg}$, i.p.) and fixed in a stereotaxic frame. Anesthesia was maintained by bolus injections of the drug at $100 \mathrm{mg} / \mathrm{kg}$ every 45-60 min. Rectal temperature was kept at $37^{\circ} \mathrm{C}$ with a heating lamp. The carbon-fiber working electrode (electrochemical probe for dopamine) was inserted through an opening in the skull to the caudate nucleus [anteroposterior (AP), $0.5 \mathrm{~mm}$; lateral (L), $2 \mathrm{~mm}$; ventral (V), $3.2 \mathrm{~mm}$ vs bregma], and a bipolar stimulating electrode was implanted in the medial forebrain bundle (MFB) (AP, $-2 \mathrm{~mm}$;, $1.2 \mathrm{~mm}$; V, 5.1-5.3 mm), according to a mouse brain atlas (Slotnick and Leonard, 1975). The exact placement of the stimulating electrode in the dorsoventral coordinate was adjusted for maximal dopamine release. A small low diffusion silversilver chloride reference electrode (DRIREF-2SH; World Precision Instruments, Sarasota, FL) in a saline bridge was placed on the skull. A stainless steel screw as the auxiliary electrode was fixed into occipital bone. After the experiments, the working electrodes were calibrated as described below, except in those cases in which the locations of the working electrodes were verified histologically after electrolytic lesions ( $6 \mathrm{~V}$ for $15 \mathrm{sec})$.

Electrochemical technique. Stimulated dopamine release was measured by constant potential amperometry with a single carbon fiber $(30 \mu \mathrm{m}$ in diameter) (World Precision Instruments) insulated with epoxy glue in pulled capillary glass. The fiber was cut to a length of $300-350 \mu \mathrm{m}$ from the end of the glass seal. A custom-built three-electrode potentiostat was used to hold the working electrode at $0.5 \mathrm{~V}$ against an $\mathrm{Ag} / \mathrm{AgCl}$ reference electrode. Data from the potentiostat were digitized and sent to a personal computer for analysis. After the experiments, the working elec-
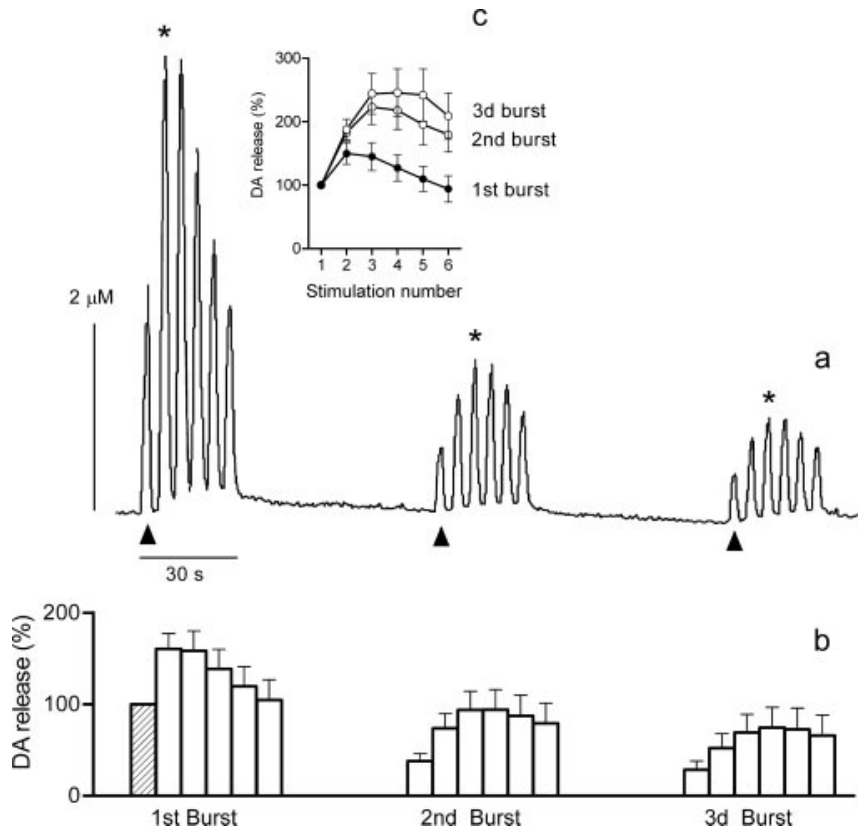

Figure 1. Different aspects of presynaptic dopamine storage and mobilization in control $\mathrm{C} 57 \mathrm{BL} / 6 \mathrm{~J}$ mice $\left(b 6 \mathrm{~m}^{+}\right)$. a, Original recording of evoked dopamine (DA) release in the caudate nucleus after repeated electrical stimulations (2 sec in length; $50 \mathrm{~Hz} ; 6$ stimulations at $5 \mathrm{sec}$ intervals) of the MFB, organized in three bursts. Arrowheads depict responses to the first stimulation in each burst. Dopamine decline at marked stimulations indicates exhaustion of the RRP by the previous burst. $b$, Summary of the data on repeated stimulations in $66 \mathrm{~m}^{+}$mice, given as percentage of dopamine release (mean $\pm S E M ; n=5$ ). The reference point (hatched bar) is the first stimulation in the first burst. This presentation of data clearly indicates that dopamine generally declines after massive stimulation. However, inside each burst, exhaustion of the RRP facilitates dopamine release. c, When the reference point is the first stimulation in each burst, progressive facilitation of dopamine release is also seen in the second and third bursts. A facilitation of release is attributed to increase in the refilling rate of the RRP. Each data point is mean $\pm \operatorname{SEM}(n=6)$.

trodes were rinsed with deionized water and calibrated for dopamine in PBS containing ascorbic acid $(200 \mu \mathrm{M}), \mathrm{pH} 7.4$.

Electrical stimulation and experimental protocol. Repeated 2 sec stimulations ( $50 \mathrm{~Hz}$; biphasic constant-current pulses; $2 \mathrm{msec}$ each) separated by $5 \mathrm{sec}$ intervals were combined in three bursts (Fig. 1a). Each burst consisted of six stimulations. Bursts were separated by 90 sec intervals. A battery-operated constant-current unit (A365; World Precision Instruments) run by a personal computer was used for a stimulation. To ensure stability of the response, this three-burst stimulation was repeated three times at $60 \mathrm{~min}$ intervals, and data from two last stimulations are presented. $\alpha$-Methyl-p-tyrosine-HCl $(\alpha \mathrm{MpT})$ (Sigma-Aldrich, St. Louis, $\mathrm{MO}$ ) at a dose of $250 \mathrm{mg} / \mathrm{kg}$ (10 ml/kg, i.p.) was administered immediately after the second application of the stimulation protocol. L-3,4Dihydroxyphenylalanine (L-dopa methyl ester hydrochloride) (SigmaAldrich) at a dose of $30 \mathrm{mg} / \mathrm{kg}$ (10 ml/kg, i.p.) was injected $20 \mathrm{~min}$ after carbidopa (15 mg/kg, i.p.; $10 \mathrm{ml} / \mathrm{kg}$; Orion Pharma, Turku, Finland) treatment. Carbidopa (free base) was prepared with a drop of Tween 80 and injected after application of the second stimulation protocol. All of the drugs were dissolved in deionized water shortly before injection.

Data presentation. Dopamine release was expressed in molar concentrations (micromolar per liter) on the basis of postcalibration data or as percentage of the evoked release. Because repeated stimulations exhaust dopamine storages and significantly reduce responses to consequent stimulations, we used two types of presentation of data in relative (percentage) format. For analysis of dopamine decline within all three of the bursts, the reference point was peak dopamine release after the very first stimulation in the first burst (Fig. $1 a$, left arrowheads, $b$, hatched bar). In this case, mainly the response to the first stimulation in each burst was used as an indicator of dopamine decline after previous burst stimulation. Dynamics of dopamine decline within each burst were expressed as 
b6m $\mathrm{m}^{+} 6 \mathrm{~m}^{+} \mathrm{h}^{+} \mathrm{m}^{+} \mathrm{h}^{+} \mathrm{m}^{+} \mathrm{hm}^{+} \mathrm{b} 6 \mathrm{~m}^{-} \mathrm{b} 6 \mathrm{~m}^{-} \mathrm{him}^{+}$

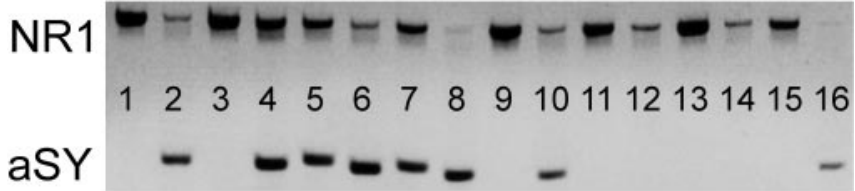

$\mathrm{h} m \mathrm{~h} \mathrm{~m} \mathrm{~h} \mathrm{~h} \mathrm{~m} \mathrm{~h} \mathrm{~m} \mathrm{~h} \mathrm{~h} \mathrm{~m} \mathrm{~h}$

Figure 2. Probing for the presence of the mouse endogenous $\alpha$-syn gene or the human $\alpha$-syn transgene in the four mouse lines. The mouse genomic $\alpha$-syn (aSY) DNA fragment (130 bp) and the human $\alpha$-syn transgene fragment (137 bp) amplified by PCR in separate reactions are shown together with positive control gene NR1 fragment (508 bp). Products were separated on a $1.8 \%$ agarose gel, so that wells with even numbers had the $P C R$ for the mouse endogenous $\alpha$-syn gene (m) and wells with odd numbers had the PCR for the human $\alpha$-syn transgene (h).

the percentage of the evoked release after the first stimulation in that particular burst (Fig. 1 $a$, arrowheads). Dynamics of dopamine decline within the second and third bursts in this case were statistically indistinguishable (Fig. 1c). For this reason, data on the second burst are not shown further in Results.

The effects of $\alpha \mathrm{MpT}$ and L-dopa were calculated in molar concentrations as a dopamine response to $2 \mathrm{sec}$ stimulation before and after the treatment. The effects of the drugs on dynamics of dopamine decline within each burst were calculated (as described above) as a percentage of evoked dopamine release after the first stimulation in each burst.

Statistical analysis. Statistical analysis was performed using multivariate ANOVA (MANOVA) for repeated measures (SPSS, Chicago, IL), with repeated electrical stimulations as the within-subjects factor (6 stimulations $\times 3$ bursts) and genotype as the between-subjects factor. The effects of drugs were analyzed similarly, using responses to repeated stimulations before and after drug administration (treatment) as the within-subjects factor (i.e., 6 stimulation $\times 3$ bursts $\times 2$ repetitions, before and after the treatment). Data are presented as mean \pm SEM.

\section{Results}

\section{Verification of $\alpha$-syn deletion and the presence of human} A30P $\alpha$-syn transgene

A genomic PCR experiment was used to confirm the presence of mouse and human $\alpha$-syn gene in the four mouse lines (Fig. 2). Amplification of genomic DNA fragments of the mouse endogenous $\alpha$-syn gene yielded the PCR product in the $b 6 m^{+}, h^{+} m^{+}$, and $h^{-} m^{+}$mouse samples. Amplification of the human $\alpha$-syn transgene fragment yielded the PCR product only in the $h^{+} \mathrm{m}^{+}$ samples. Additionally, amplification of either genomic DNA fragment of mouse endogenous $\alpha$-syn gene or the human $\alpha$-syn transgene yielded no PCR products in the $b 6 \mathrm{~m}^{-}$samples.

\section{General approach to characterization of presynaptic dopamine storage and mobilization}

Repeated electrical stimulations (delivered in bursts) and realtime monitoring of dopamine release were used as tools to assess the capacity of the storage pool and to estimate the refilling rate of the RRP (Yavich, 1996; Yavich and MacDonald, 2000). In $\mathrm{brm}^{+}$ mice used as the reference line (Fig. $1 a-c$ ), progressively decreased responses to the first stimulation in each burst (Fig. $1 a$, arrowheads) reflect the amount of dopamine available for immediate release after a depletion induced by previous burst(s). Taking peak dopamine release after the very first stimulation as a reference point (100\%) (Fig. 1b, hatched bar), this depletion in the response to the first stimulation of each consecutive burst can be seen clearly and reaches statistical significance in $b_{6 m}^{+}$and other lines except $b 6 m^{-}$(see below). The subsequent peaks within the bursts demonstrate the process of presynaptic dopamine mobilization (Yavich, 1996; Yavich and MacDonald, 2000).

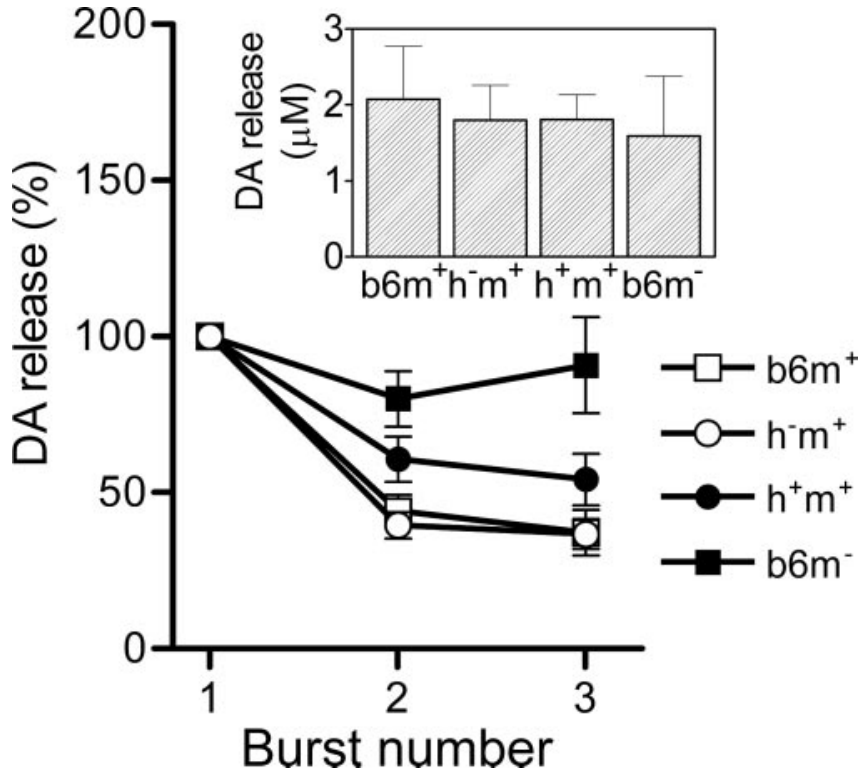

Figure 3. The capacity of the RRP determined by dopamine (DA) decline after repeated stimulation of the medial forebrain bundle. Three bursts of stimulations were applied to the MFB according to the stimulation protocol described in Figure 1 and Materials and Methods. These massive stimulations exhausted the RRP and to some extent the dopamine storage and induced a decline in the evoked dopamine levels in all of the mouse lines except $b 6 m^{-}$. Data are given as percentage of dopamine release after the first stimulation in the first burst. Each data point represents the relative level of dopamine after the first stimulation in each consecutive burst (numbers 1-3 on the horizontal axis). The inset shows dopamine release after single $2 \mathrm{sec}$, $50 \mathrm{~Hz}$ stimulation, expressed in molar concentrations (means $\pm \mathrm{SEM} ; n=5-8$ per group).

Dopamine release was increased after repeated stimulations at 5 sec intervals, relative to the first stimulation in each burst (Fig. $1 a, c)$. The second and the third bursts demonstrated larger facilitation of dopamine release compared with the first burst. A decline in dopamine release within the bursts was also seen. Facilitation of dopamine release after repeated stimulation within the bursts is caused by the activation of the storage pool and can serve as an index for the rate of refilling of the RRP.

\section{Comparison of presynaptic dopamine storage and} mobilization among the four $\mathrm{C} 57 \mathrm{BL} / 6$ mouse lines Measured as a peak dopamine release after the first stimulation in each burst (Fig. 1 $a$, arrowheads), dopamine responses gradually declined from the first to the third burst in all three lines that have the mouse $\alpha$-syn $\left(b 6 m^{+}, h^{+} m^{+}\right.$, and $\left.h^{-} m^{+}\right)$but was not significantly changed in knock-out $b 6 \mathrm{~m}^{-}$mice (Fig. 3) (stimulation and genotype interaction, $F_{(6)}=2.4, p<0.045$; main effect of stimulation in $b 6 m^{-}$mice, $\left.F_{(2)}=3.8, p<0.2\right)$. The MANOVA revealed a significant between-subjects effect of the genotype $\left(F_{(3)}=5.8 ; p<\right.$ 0.006). The differences between the lines were independent of the initial levels of dopamine release, which were practically the same in all of the lines in response to single $2 \mathrm{sec}$ stimulation (Fig. 3, inset) $\left(F_{(3)}=0.3 ; p<0.8\right)$.

Because $b 6 m^{-}$mice had such distinct responses to the first stimulation in the bursts, we initially compared dopamine release on each repeated stimulation between $b 6 \mathrm{~m}^{-}$and other lines in an "absolute" scale, i.e., data were presented as a percentage of dopamine release after the very first stimulation (Fig. 4, asterisk). The $b 6 m^{-}$mice released more dopamine on repeated stimulations than the $b_{6 m} \mathrm{~m}^{+}$controls (Bonferroni multiple comparisons between genotypes; $p<0.013$ ) and also the two other lines, which demonstrated very similar responses to those of $b_{6 m}^{+}$mice 

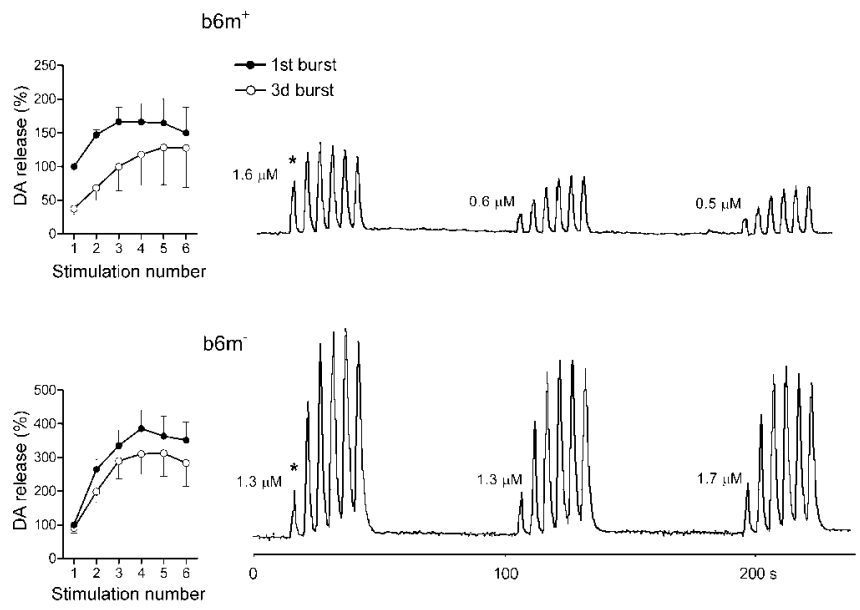

Figure 4. Comparison of presynaptic dopamine compartmentalization in C57BL/6J $\alpha$-syn knock-out $\left(b_{6 m^{-}}\right)$and control $\left(b 6 m^{+}\right)$mice. Right, Original recordings of evoked dopamine (DA) release after repeated stimulations in a representative mouse from each line. Examples were chosen on the basis of similar initial molar levels of extracellular dopamine after the first stimulation (marked by asterisk). The numbers show molar dopamine concentrations at the first peak of each burst. Left, Summaries of results in these two mouse lines. Data are presented as percentage in reference to the first peak of the first burst (marked by an asterisk). Each data point is mean \pm SEM ( $n=5-6$ per group).

(b6m- vs $h^{-} m^{+}, p<0.021 ; b 6 m^{-}$vs $h^{+} m^{+}, p<0.007$ ) (for original recordings of the most typical responses in $b 6 \mathrm{~m}^{-}$and $b_{6 m} \mathrm{~m}^{+}$mice, see Fig. 4).

Despite similar absolute levels of dopamine released on single stimulations, mouse lines carrying the mouse $\alpha$-syn $\left(b 6 m^{+}\right.$, $h^{-} m^{+}$, and $h^{+} m^{+}$) differed in the dynamics of dopamine release in the first and the third burst (bursts and genotype interaction, $\left.F_{(2)}=4.0 ; p<0.05\right) . b 6 m^{+}$and $h^{-} m^{+}$mice showed moderate facilitation of dopamine release within the first burst and an additional increase in the third burst. Figure 5 depicts the data as percentage of release after the first stimulation in each burst to show the dynamics of dopamine release within the burst, which reflect primarily the rate of the refilling of the RRP and secondarily the capacity of the reserve pool. $h^{+} m^{+}$mice also demonstrated a moderate facilitation of dopamine release in the first burst but had similar dynamics of dopamine release at the first and the third burst (main effect of burst, $F_{(1)}=0.5 ; p<0.5$ ). Finally, $b 6 \mathrm{~m}^{-}$mice showed more than twice as much facilitation of dopamine release at the first burst as the other lines (genotype, test of between-subjects effects, $b 6 \mathrm{~m}^{-}$mice vs all of the other breeds; $p<0.01$ ) and, in contrast to other lines, a trend toward reduced facilitation of dopamine release at the third burst (Fig. 5) (main effect of burst, $F_{(1)}=1.9 ; p<0.2$ ). Thus, both $b 6 \mathrm{~m}^{-}$ (knock-out) and $h^{+} m^{+}$(transgenic) mice demonstrated the absence of additional facilitation of dopamine release at the third burst compared with the first one.

\section{The effects of pharmacological modulation of presynaptic dopamine on dopamine recruitment}

In these experiments, $b 6 m^{+}$and $h^{+} m^{+}$mice were treated with $\alpha \mathrm{MpT}$ and L-dopa. $\alpha \mathrm{MpT}$ depletes RRP and, in principle, should have the same effects on the dopamine overflow as a series of repeated stimulations in the previous experiments, i.e., facilitation of dopamine release. The $\alpha \mathrm{MpT}$ treatment $(250 \mathrm{mg} / \mathrm{kg}$ ) predictably decreased absolute levels of dopamine induced by single stimulations in both mouse lines (Fig. 6, middle). In $\mathrm{b}^{+} \mathrm{m}^{+}$mice, the treatment facilitated dopamine release in the first burst (Fig. 6 , left) (main effect of treatment, $F_{(1)}=7.9 ; p<0.05$ ). In con- trast, $h^{+} m^{+}$mice showed no facilitation after $\alpha \mathrm{MpT}$ injection (Fig. 6, right) (main effect of treatment, $F_{(1)}=0.5 ; p<0.5$ ) and, thus, differed from $b 6 \mathrm{~m}^{+}$mice (treatment and genotype interaction, $\left.F_{(1)}=6.0 ; p<0.05\right)$.

Treatment with L-dopa $(30 \mathrm{mg} / \mathrm{kg})$, a drug increasing the amount of dopamine in the cytosol, predictably increased dopamine release in terms of molar concentrations after single stimulations in both genotypes (Fig. 7, middle). In $b 6 m^{+}$mice, L-dopa did not change the facilitation of dopamine release in the bursts (Fig. 7, left) (main effect of treatment, $F_{(1)}=0.3 ; p<0.6$ ). However, $\mathrm{L}$-dopa decreased facilitation of dopamine release within the bursts in $h^{+} m^{+}$mice (Fig. 7, right) (main effect of treatment, $F_{(1)}=9.9 ; p<$ $0.05)$, resulting in significant treatment and genotype interaction $\left(F_{(1)}=6.7 ; p<0.05\right)$.

\section{Discussion}

\section{Dopamine decline after massive stimulation depends on the} $\alpha$-syn genotype

Mice with altered $\alpha$-syn genotype differed from control C57BL/6J mice in their dynamics of dopamine decline after massive stimulation (Fig. 3), with the largest differences apparent between $\mathrm{b}^{+} \mathrm{m}^{+}$and $\mathrm{b6m} \mathrm{m}^{-}$mice. According to our hypothesis based on our previous experiments in Wistar rats (Yavich and MacDonald, 2000) and BALB/c mice (Yavich, 1996), the dopamine decline between the bursts was caused by exhaustion of the RRP. Thus, results summarized in Figure 3 (no decline of the first peaks at the bursts in $b 6 \mathrm{~m}^{-}$mice) are consistent with the suggestion that $b 6 \mathrm{~m}^{-}$mice have the largest RRP of dopamine among the tested C57BL/6 lines. We also expected to find the largest extracellular dopamine concentration in response to a single stimulation in $b_{6 m} \mathrm{~m}^{-}$mice; however, variations in the electrode location and known heterogeneity of release in the caudate (May and Wightman, 1989) did not allow us to perform reliable betweensubjects comparisons of extracellular dopamine concentrations. An alternative explanation for the results is a faster refilling rate of the RRP and/or a larger storage pool of dopamine in $b^{-} \mathrm{m}^{-}$mice. This explanation does not require that dopamine release after single stimulation should be larger, and it is also supported by the analysis of dopamine release within the bursts (see below).

\section{Facilitation of dopamine release within the bursts as an index of the RRP refilling rate and different capacity of the storage pool}

Refilling of the RRP restores its capacity. The rate of refilling confines neurotransmission after bursting or trains of stimulations repeated at short intervals (Wang and Kaczmarek, 1998; Stevens and Wesseling, 1999). It is well known that reuptaken dopamine constitutes a part of the RRP. In our preparation, reuptake is fully functional. Moreover, we did not find differences in the degree of dopamine reuptake between the lines (data not shown). In slice or cell preparations, reuptake is less efficient because of diffusion of dopamine from the sites of release to the medium, which in turn can decrease the extents of dopamine storages. This situation might be reproduced, even in intact brain, in areas with less efficient reuptake (e.g., nucleus accumbens vs caudate) (Yavich and MacDonald, 2000) or after treatment with reuptake inhibitors (our unpublished observations). However, even in the case in which no absolute increase of dopamine is detected after repeated stimulation (in some particular preparations or after treatment with reuptake inhibitors), dopamine decline is retarded after repeated stimulation at short intervals. This phenomenon was described by Abeliovich et al. (2000) in slices of $\alpha$-syn knock-out mice after paired-pulse stimulations 

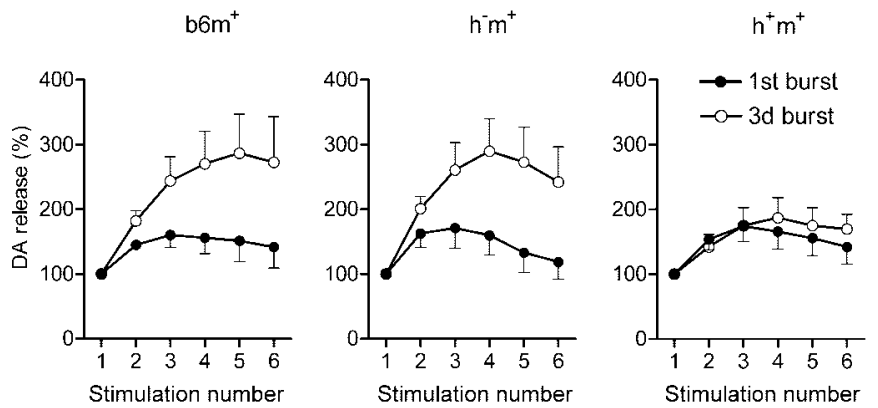

Figure 5. Activation of the refilling rate of the RRP in the four mouse lines in response to repeated stimulations. Evoked dopamine (DA) release after repeated stimulation in the first and the third bursts shown as group data (each data point is mean \pm $\mathrm{SEM} ; n=5-9$ per group). Data are presented as percentage in reference to the first peak of each burst and thus describe the dynamics of dopamine release within the burst.
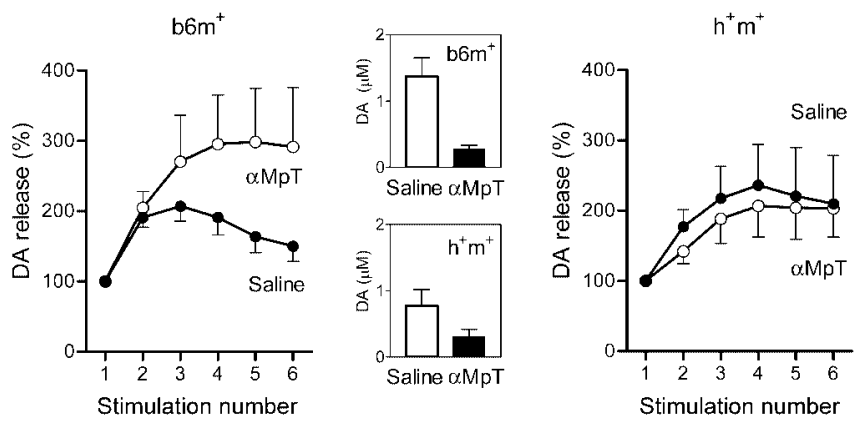

Figure 6. The effects of $\alpha \mathrm{MpT}(250 \mathrm{mg} / \mathrm{kg})$ on the refilling rate of the RRP in transgenic mice with overexpression of human mutated A30P $\alpha$-syn $\left(\mathrm{h}^{+} \mathrm{m}^{+}\right)$and in control $\mathrm{C57BL} / 6\left(\mathrm{~b} 6 \mathrm{~m}^{+}\right)$ mice. Evoked dopamine $(\mathrm{DA})$ release after repeated stimulations shown for the first burst before and the first burst 60 min after the administration of drug as group data (each data point is mean \pm SEM; $n=6-9$ per group). The dynamics of dopamine release within the burst are presented as a percentage, as in Figure 5. $\alpha \mathrm{MpT}$ treatment exhausted the RRP and decreased evoked dopamine release. Insets show the effects of drug on dopamine release evoked by $2 \mathrm{sec}$, $50 \mathrm{~Hz}$ single stimulation in molar concentrations as means \pm SEM (open bar, before treatment in $b 6 \mathrm{~m}^{+}$and $\mathrm{h}^{+} \mathrm{m}^{+}$mice; filled bar, after treatment in $b 6 \mathrm{~m}^{+}$and $\mathrm{h}^{+} \mathrm{m}^{+}$mice). The treatment increased the RRP refilling rate in $66 \mathrm{~m}^{+}$mice and did not change the dynamics of dopamine release in transgenic mice, which corresponds with the effects of repeated stimulation in transgenic and knock-out mice in the previous experiment shown in Figure 5.
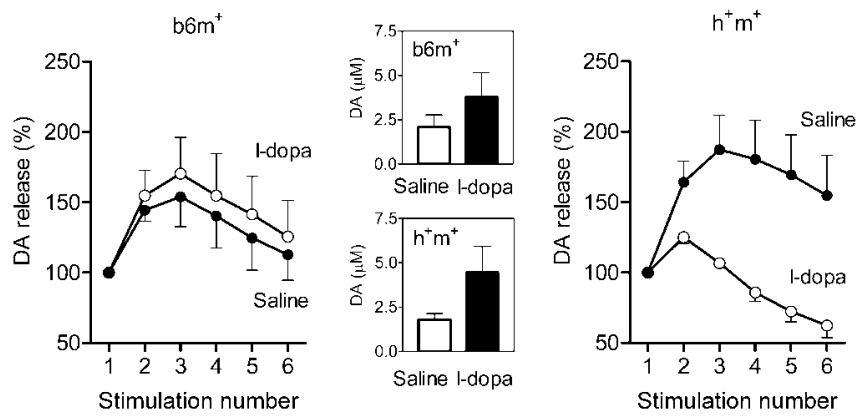

Figure 7. The effects of $\mathrm{L}-\mathrm{dopa}(30 \mathrm{mg} / \mathrm{kg})$ on the refilling rate of the RRP in transgenic $\left(h^{+} \mathrm{m}^{+}\right)$and control $\left(b 6 \mathrm{~m}^{+}\right)$mice. Data are presented in the same manner as in Figure $6(n=$ 5 per group). The effects of $\mathrm{L}$-dopa on facilitation of dopamine (DA) release during the first burst were analyzed $40 \mathrm{~min}$ after treatment ( $\mathrm{L}$-dopa was injected $20 \mathrm{~min}$ after carbidopa). Treatment increased evoked dopamine release after single stimulation (insets), did not change the refilling rate of the RRP in $b 6 m^{+}$mice, and decreased it in $h^{+} m^{+}$mice.

at 5-20 sec. The first reliable mathematical model of this short-term plasticity of dopamine release was presented recently (Montague et al., 2004). Facilitation of dopamine release after paired-pulse stimulation at ultrashort intervals $(10 \mathrm{msec})$, described in striatal slices in

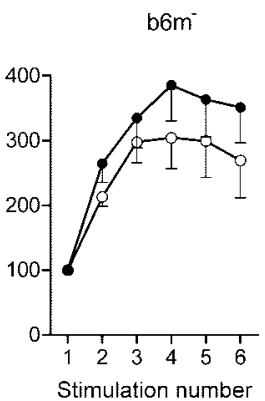

marmoset, can be only partly explained by participation of the RRP, because it is not modulated by reuptake inhibition (Cragg, 2003). Indeed, it is possible that $10 \mathrm{msec}$ is too short an interval for the reuptake to play a role in the refilling of the RRP.

A detailed analysis of dopamine release within the first and the third burst in our experiments revealed two interesting phenomena: (1) facilitation of dopamine release in response to stimulations at short intervals within the first burst and (2) additional facilitation of release during the second and third burst (Fig. 1c). The first finding confirmed our previous results and likely derives from enhanced refilling rate of the RRP after the exhaustion of this pool (Yavich, 1996; Yavich and MacDonald, 2000). This would also be the most parsimonious explanation for the second finding: the previous two bursts exhausted the RRP and led to additional elevation of the refilling rate. Data on the effects of $\alpha \mathrm{MpT}$ support this hypothesis. This drug, which decreases the contents of dopamine in the RRP, induced facilitation of dopamine release in $b 6 \mathrm{~m}^{+}$mice in the same way as a massive stimulation.

The effects of $\alpha \mathrm{MpT}$ in $b 6 m^{+}$(facilitation of release after treatment) and $h^{+} m^{+}$(no additional facilitation) were similar to and supportive of the data obtained after burst stimulation. Namely, in both control mouse lines $\left(66 \mathrm{~m}^{+}\right.$and $\left.h^{-} \mathrm{m}^{+}\right)$, dopamine release at the third burst was larger than at the first burst, whereas, in $\alpha$-syn knock-out $\left(b 6 m^{-}\right)$and transgenic $\left(h^{+} m^{+}\right)$ mice, it was statistically indistinguishable. These effects of $\alpha \mathrm{MpT}$ cannot be attributed to the differences in $\mathrm{TH}$ activity between the mouse lines, because the effects of $\alpha \mathrm{MpT}$ on dopamine release in response to single stimulation were similar in transgenic and $b_{6 m}{ }^{+}$control animals (Fig. 6, middle). Furthermore, there is no difference between transgenic and control mice in the intensity of TH staining (Jakala et al., 2002). Together, these findings indicate that both $b_{6 m}^{-}$and $h^{+} m^{+}$mice have limited capacity of the dopamine storage pool.

\section{Elevation of the RRP refilling rate in $\alpha$-syn knock-out mice}

A threefold to fourfold facilitation of dopamine release within the first and third burst indicates that the refilling rate of the RRP is permanently elevated in $b 6 \mathrm{~m}^{-}$mice (compare the similarity in facilitation of release between the third burst in the $b 6 \mathrm{~m}^{+}$mice and the first burst in $b 6 \mathrm{~m}^{-}$mice). Thus, because of the higher refilling rate of the RRP in $b 6 m^{-}$mice, effects of activation do not subside during the $90 \mathrm{sec}$ interburst intervals. Therefore, facilitation of dopamine release caused by elevation of the refilling rate dominates over the decline induced by massive stimulation in $b 6 \mathrm{~m}^{-}$mice. As a result, $b 6 \mathrm{~m}^{-}$mice did not demonstrate any dopamine decline at the chosen parameters of stimulations. We believe that this mechanism serves to adapt the mice to the null mutation. A relative increase in the amount of vesicular transporter per available storage vesicle can be one of the molecular mechanisms of this facilitation.

\section{L-dopa decreases the RRP refilling rate in mice with mutated human $\alpha$-syn}

Whereas L-dopa increased dopamine release in response to a single stimulation, no changes in the dynamics of dopamine release were observed within the bursts in $b_{6 m} \mathrm{~m}^{+}$mice. Indeed, one would expect some decrease in the RRP refilling rate, at least 
during the first burst, because L-dopa increases the RRP capacity. The failure to detect any such decrease may indicate that, in relation to the original capacity of the RRP, the fraction of dopamine elevated by L-dopa treatment at a dose of $30 \mathrm{mg} / \mathrm{kg}$ did not significantly contribute to the capacity of the RRP in $b_{6 m} \mathrm{~m}^{+}$mice. Accordingly, the reduced capacity of the storage pool in $h^{+} m^{+}$ mice led to the paradoxical effects of L-dopa, which further decreased their ability to maintain dopamine overflow during a long run of repeated stimulations. These effects of L-dopa in $h^{+} \mathrm{m}^{+}$mice may be relevant to some clinical paradoxes of L-dopa treatment.

In summary, we found variations in presynaptic dopamine compartmentalization and recruitment between mouse lines with abnormal $\alpha$-syn genotypes and their congenic controls. The absence of the endogenous mouse $\alpha$-syn and the presence of a transgenic mutated human $\alpha$-syn resulted in altered compartmentalization of presynaptic dopamine. The elevation of the refilling rate of the RRP in null mutated mice serves as an adaptive mechanism to compensate for this alteration, probably at the expense of decreasing the amount of vesicles in the reserve pool. We suggest that development of dopamine deficiency (e.g., in Parkinson's disease) would also elevate the refilling rate of the RRP. Our results predict that both $b 6 \mathrm{~m}^{-}$and $h^{+} \mathrm{m}^{+}$mice (i.e., mice without $\alpha$-syn or with additional human mutated $\alpha$-syn) could behave normally in situations in which the activity of dopamine neurons is low but would fail in the tasks that require prolonged bursting of dopamine neurons. Furthermore, L-dopa would paradoxically weaken their performance in such behavioral tasks.

\section{References}

Abeliovich A, Schmitz Y, Farinas I, Choi-Lundberg D, Ho WH, Castillo PE, Shinsky N, Verdugo JM, Armanini M, Ryan A, Hynes M, Phillips H, Sulzer D, Rosenthal A (2000) Mice lacking alpha-synuclein display functional deficits in the nigrostriatal dopamine system. Neuron 25:239-252.

Cabin DE, Shimazu K, Murphy D, Cole NB, Gottschalk W, McIlwain KL, Orrison B, Chen A, Ellis CE, Paylor R, Lu B, Nussbaum RL (2002) Synaptic vesicle depletion correlates with attenuated synaptic responses to prolonged repetitive stimulation in mice lacking $\alpha$-synuclein. J Neurosci 22:8797-8807.

Cragg SJ (2003) Variable dopamine release probability and short-term plasticity between functional domains of the primate striatum. J Neurosci 23:4378-4385.

Ewing AG, Bigelow JC, Wightman RM (1983) Direct in vivo monitoring of dopamine released from two striatal compartments in the rat. Science 221:169-171.

Jakala P, Puolivali J, Kerokoski P, van Groen T, Beyreuther K, Hartmann T (2002) Intracellular a-synuclein (A-SYN) accumulation in transgenic mice expressing A30P a-synuclein mutation. Neurobiol Aging 23:S252.

Kruger R, Kuhn W, Muller T, Woitalla D, Graeber M, Kosel S, Przuntek H, Epplen JT, Schols L, Riess O (1998) Ala30Pro mutation in the gene encoding alpha-synuclein in Parkinson's disease. Nat Genet 18:106-108.

Lotharius J, Brundin P (2002a) Impaired dopamine storage resulting from alpha-synuclein mutations may contribute to the pathogenesis of Parkinson's disease. Hum Mol Gen 11:2395-2407.

Lotharius J, Brundin P (2002b) Pathogenesis of Parkinson's disease: dopamine, vesicles and alpha-synuclein. Nat Rev Neurosci 3:932-942.

May LJ, Wightman RM (1989) Heterogeneity of stimulated dopamine overflow within rat striatum as observed with in vivo voltammetry. Brain Res 487:311-320.

Montague PR, McClure SM, Baldwin PR, Phillips PE, Budygin EA, Stuber GD, Kilpatrick MR, Wightman RM (2004) Dynamic gain control of dopamine delivery in freely moving animals. J Neurosci 24:1754-1759.

Murphy DD, Rueter SM, Trojanowski JQ, Lee VM-Y (2000) Synucleins are developmentally expressed, and $\alpha$-synuclein regulates the size of the presynaptic vesicular pool in primary hippocampal neurons. J Neurosci 20:3214-3220.

Polymeropoulos MH, Lavedan C, Leroy E, Ide SE, Dehejia A, Dutra A, Pike B, Root H, Rubenstein J, Boyer R, Stenroos ES, Chandrasekharappa S, Athanassiadou A, Papapetropoulos T, Johnson WG, Lazzarini AM, Duvoisin RC, Di Iorio G, Golbe LI, Nussbaum RL (1997) Mutation in the alphasynuclein gene identified in families with Parkinson's disease. Science 276:2045-2047.

Rosenmund C, Stevens CF (1996) Definition of the readily releasable pool of vesicles at hippocampal synapses. Neuron 16:1197-1207.

Slotnick BM, Leonard CM (1975) A stereotaxic atlas of the albino mouse forebrain. Rockville, Maryland: Public Health Service, United States Department of Health, Education, and Welfare.

Specht CG, Schoepfer R (2001) Deletion of the alpha-synuclein locus in a subpopulation of C57BL/6J inbred mice. BMC Neurosci 2:11.

Stevens CF, Wesseling JF (1998) Activity-dependent modulation of the rate at which synaptic vesicles become available to undergo exocytosis. Neuron 21:415-424.

Stevens CF, Wesseling JF (1999) Identification of a novel process limiting the rate of synaptic vesicle cycling at hippocampal synapses. Neuron 24:1017-1028.

Wang LY, Kaczmarek LK (1998) High-frequency firing helps replenish the readily releasable pool of synaptic vesicles. Nature 394:384-388.

Yavich L (1996) Two simultaneously working storage pools of dopamine in mouse caudate and nucleus accumbens. Br J Pharmacol 119:869-876.

Yavich L, MacDonald E (2000) Dopamine release from pharmacologically distinct storage pools in rat striatum following stimulation at frequency of neuronal bursting. Brain Res 870:73-79.

Zucker RS (1999) Calcium- and activity-dependent synaptic plasticity. Curr Opin Neurobiol 9:305-313. 